\title{
ANÁLISE DA OCUPAÇ̃̃O URBANA E DA PERCEPÇ̃̃O DOS MORADORES FRENTE À INFRAESTRUTURA LOCAL NO LOTEAMENTO PARQUE MAMBUCABA EM ANGRA DOS REIS - RJ
}

\section{Analysis of the urban occupation and the perception of residents of the local infrastructure in the Parque Mambucaba neighborhood, Angra dos Reis/RJ}

\author{
Luiz Miguel Stumbo Filho \\ Bacharel em Geografia pela UFRRJ/DEGEO/IM \\ luizmiguelsf@gmail.com
}

Eduardo Gustavo Soares Pereira

Graduando em Geografia pela USP

eduvcd@gmail.com

Monika Richter

Professora Adjunto IV do Depto. de Geografia do Instituto Multidisciplinar da UFRRJ mrichter84@hotmail.com

Artigo enviado para publicação em 21/06/2017 e aceito em 21/03/2018

DOI: $10.12957 /$ tamoios.2018.29046

\section{Resumo}

A implantação das Usinas Nucleares e da Rodovia Rio-Santos, constituem-se nos principais vetores de ocupação do distrito de Mambucaba, localizado ao sul do município de Angra dos Reis/RJ. A construção e operação de Angra I e II e mais recentemente com o início das obras de Angra III, trouxeram grande quantidade de mão-de-obra, acarretando um crescimento acentuado da população. Em 1970, Mambucaba apresentava população de 880 habitantes, em boa parte caracterizada como rural; atualmente possui mais de 17 mil habitantes em áreas urbanas, segundo o Censo de 2010 do IBGE. Neste contexto, o presente trabalho teve como objetivo realizar uma análise da ocupação urbana do loteamento Parque Mambucaba, mais populoso do distrito, no período entre 2005 e 2016, considerando os conflitos de uso, tais como ocupação em área de preservação permanente e áreas sujeitas a inundações. Também foram levantados dados sobre a percepção dos moradores relacionados aos aspectos da infraestrutura local: unidades escolares e hospitalares, coleta de lixo e transporte público. Os resultados apontam que, no total de 2573 lotes, 107 ocupam as margens do rio Mambucaba, ou seja, inseridos na condição que deveria ser de preservação permanente, e 47,1\% encontram-se em áreas sujeitas a inundação. Destaca-se ainda que no período de tempo analisado, houve um incremento em 19\% de lotes totalmente ocupados. Quanto aos serviços básicos, somente a coleta de lixo apresentou resultado satisfatório na percepção dos moradores entrevistados.

Palavras-chave: Parque Mambucaba; Ocupação Urbana e Geoprocessamento

\begin{abstract}
The construction of the Nuclear Power Plants and the implementation of the Rio-Santos Highway are the main occupation vectors of the Mambucaba district, located south of Angra dos Reis / RJ. The construction and operation of Angra I and II had attracted a large amount of labor, leading to a sharp increase in population. In 1970, Mambucaba had a population of 880 habitants jumping to more than 17 thousand, according to the recent IBGE Census. The present work had the objective of analyzing the urban occupation of the Mambucaba Park, between 2005 and 2016, considering the conflicts of use such as occupation in permanent preservation area and areas subject to floods. Data were also collected on the perception of residents regarding aspects of local infrastructure, such as school and hospital units, garbage collection and public transportation. The results indicate that, in a total of 2573 building sits, 107 occupy the banks of the Mambucaba River and $47.1 \%$ are in areas subject to flooding. It should also be noted that in the time period analyzed, there was an increase of $19 \%$ of fully occupied building sits. As for basic services, only garbage collection presented a satisfactory result
\end{abstract}

Keywords: Parque Mambucaba, Urban Occupation and Geoprocessing 


\section{INTRODUÇÃO}

Na década de 70, três grandes projetos foram implantados em Angra dos Reis/RJ, os quais causaram significativas transformações sócio-espaciais no município (Abreu, 2005). O primeiro projeto foi a construção da Rio-Santos, BR-101, rodovia que fez a integração do município à capital do estado. O segundo foi a instalação do terminal marítimo da Petrobras (TEBIG) e por último a Usina Nuclear Angra I no final dos anos 70. Esta, atraiu grande quantidade de mão-de-obra vinda de diferentes locais, acarretando um crescimento acentuado da população, principalmente no distrito de Mambucaba, onde está localizada a Usina.

Segundo o IBGE, em 1970, a população de Mambucaba correspondia a aproximadamente 880 habitantes, sendo que $89 \%$ rural. Em 1980, a população passa para 3,5 mil habitantes, com uma taxa de crescimento de $14 \%$ ao ano. Porém, com o fim da construção de Angra I, em 1982, boa parte da mão-de-obra foi liberada para outras atividades que não conseguiu ser absorvida pelo mercado de trabalho local; o mesmo aconteceu após a construção de Angra II. Além disso, essas pessoas vão residir nos bairros no entorno do empreendimento, que muitas vezes não possuem infraestrutura adequada para receber um contingente populacional maior.

Devido a esse processo, o ônus relativo à infraestrutura básica recai sobre o poder público municipal que precisa atender as demandas principalmente de saúde, educação e transporte. Os constantes conflitos que ocorreram e ainda ocorrem entre população e a administração pública local resultaram no movimento de emancipação do distrito de Mambucaba em 2006, e novo movimento de reabertura do processo em 2013. Acrescentase ainda os embates pela posse de terra, fruto de uma forte especulação imobiliária, provocada pela valorização das áreas de planícies, escassas no município de Angra.

De acordo com a contagem do IBGE de 2010, o distrito possui mais de 17,7 mil habitantes, o que tende a aumentar muito em decorrência da construção da Usina Angra III, que se encontra em andamento. Outro fator indicativo do crescimento local foi a inauguração do Centro Federal de Educação Tecnológico Celso Suckow da Fonseca CEFET, oferecendo cursos técnicos em Engenharia Mecânica e Bacharelado em Engenharias.

Diante do exposto, o presente trabalho teve como objetivo realizar uma análise da ocupação urbana do loteamento Parque Mambucaba (Figura 01), maior em área e o mais populoso do distrito Mambucaba, localizado na porção oeste do município de Angra dos Reis/RJ, tendo como base a disponibilidade de ortofoto de 2005 (IBGE) e imagem de satélite de alta resolução espacial de 2016 (WVII - PMAR).

Também foram analisados os conflitos de ocupação considerando as áreas de preservação permanente (APPs) destacando-se as relacionadas as margens do rio Mambucaba e as áreas sujeitas a inundações segundo levantamentos da Defesa Civil Municipal. Foram tambem aplicados questionários junto à comunidade residente objetivando avaliar a percepção dos moradores em relação aos aspectos da infraestrutura básica, tais como escolas, postos de saúde, coleta de lixo dentre outros. 


\section{Loteamento Parque Mambucaba-Angra dos Resis/}

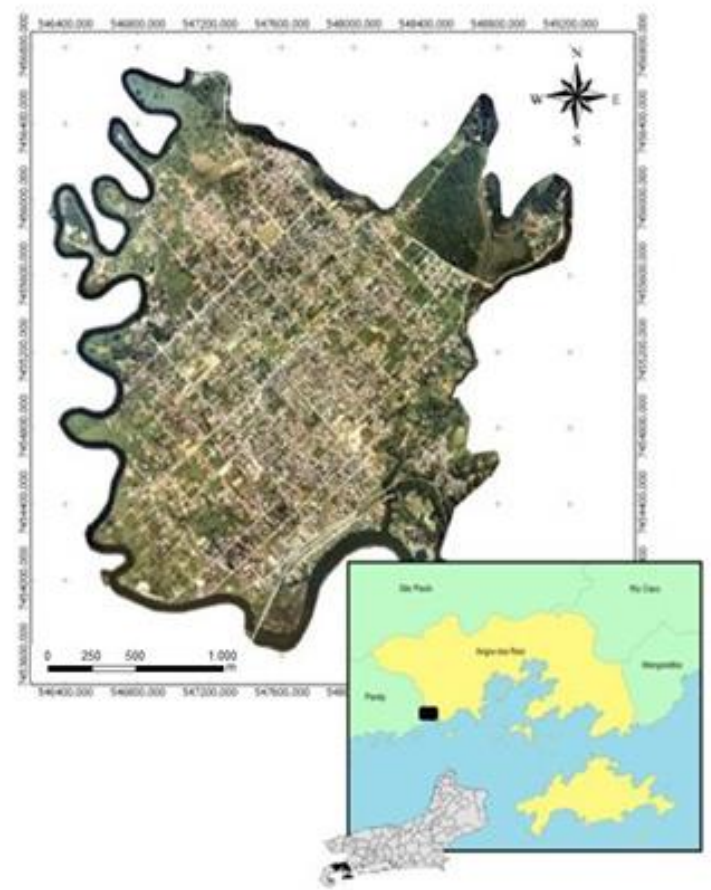

Figura 01. Localização do loteamento Parque Mambucaba em Angra dos Reis/RJ

Fonte dos Dados: Ortofoto e mapa do estado do Rio de Janeiro - IBGE (https://downloads.ibge.gov.br/downloads_geociencias.htm)

\section{MATERIAIS E MÉTODOS}

Para o desenvolvimento do trabalho (figura 02), primeiramente foram realizados levantamentos de dados junto a Prefeitura de Angra dos Reis (PMAR), bem como na internet, nas páginas da própria Prefeitura e do IBGE. Nesta, foi obtida ortofoto no formato .tiff, disponibilizada gratuitamente e datada de 2005, a malha dos setores censitário de 2010 e dados de contagem populacional; e pela PMAR, dados cartográficos como: arruamento, lotes, curvas de nível, hidrografia, macrozoneamento e zoneamento territorial, dentre outros no formato.$d w g$ relativos ao loteamento Parque Mambucaba e imagem de base orbital do World View II de alta resolução espacial do referente ao ano de 2016. Ressalta-se que tal loteamento foi aprovado na década de 70, já prevendo a demanda de ocupação que haveria tanto pela implantação da rodovia Rio-Santos quanto pela construção das Usinas Nucleares.

Também foram pesquisados os instrumentos de planejamento urbano tais como o Zoneamento em sua representação cartográfica e o memorial que o acompanha para compreender a ótica do Poder Público local no processo de uso e ocupação do Parque Mambucaba. Além destes, obteve-se junto à Defesa Civil a relação das ruas sujeitas a inundações, considerada atualmente como um dos mais graves problemas socioambientais do bairro, as quais foram posteriormente vetorizadas sobre a base do arrumamento.

Após a conversão da base cartográfica do loteamento Parque Mambucaba para shapefile, os dados foram organizados e processados no programa livre de SIG Quantum GIS versão 2.8. Foram gerados mapas temáticos de área de preservação permanente (APP) do rio Mambucaba (50m segundo o novo Código Florestal de 2012), situação do 
loteamento em termos de ocupação do solo a partir da sobreposição da planta de loteamento e a ortofoto (2005) e a imagem do World View II (2016), mapa de conflito ambiental (ocupação em APP), das áreas (lotes) sujeitas a inundação, e mapa de densidade populacional por setor censitário a partir dos dados do IBGE de 2010. Este último classificado em alta, média e baixa densidade, sendo estas classes definidas a partir da aplicação do recurso de quebras naturais, onde consiste basicamente na miminização da soma da variância dentro de cada classe a partir de uma fórmula estatística denominada Otimização de Jenks (DENT et al, 2009). As classes definidas foram: a) alta densidade (77 a 130 hab/ha); média densidade (29 a 76 hab/ha) e c) baixa densidade (de 0 a 28hab/ha)

Considerando a escala cartográfica deste último (mapa dos setores), e da ortofoto do IBGE, a menor dos dados originais/primários, os produtos cartográficos gerados encontram-se na escala 1:25.000, adotando-se o sistema de referência de coordenada UTM 23S / SIRGAS 2000.

Em relaçao aos critérios utilizados para a classificação da taxa de ocupação nos lotes, em sua maioria com $360 \mathrm{~m} 2$ de área $(12 \times 30 \mathrm{~m})$, foram definidos a partir da visualização das imagens (tanto a ortofoto do IBGE quanto do World View II) coletadas para o trabalho, com a sobreposição da Planta de Loteamento Parque Mambucaba. São estes: (i) áreas onde não havia construções ou outras intervenções foram consideradas como não ocupados (abaixo de 30\% da área do lote definida em planta); (ii) áreas onde existiam poucas construções ou intervenções (em torno de 30-70\% da área do lote definida em planta) foram consideradas parcialmente ocupadas; e (iii) áreas totalmente modificadas (acima de $70 \%$ da área do lote definida em planta).

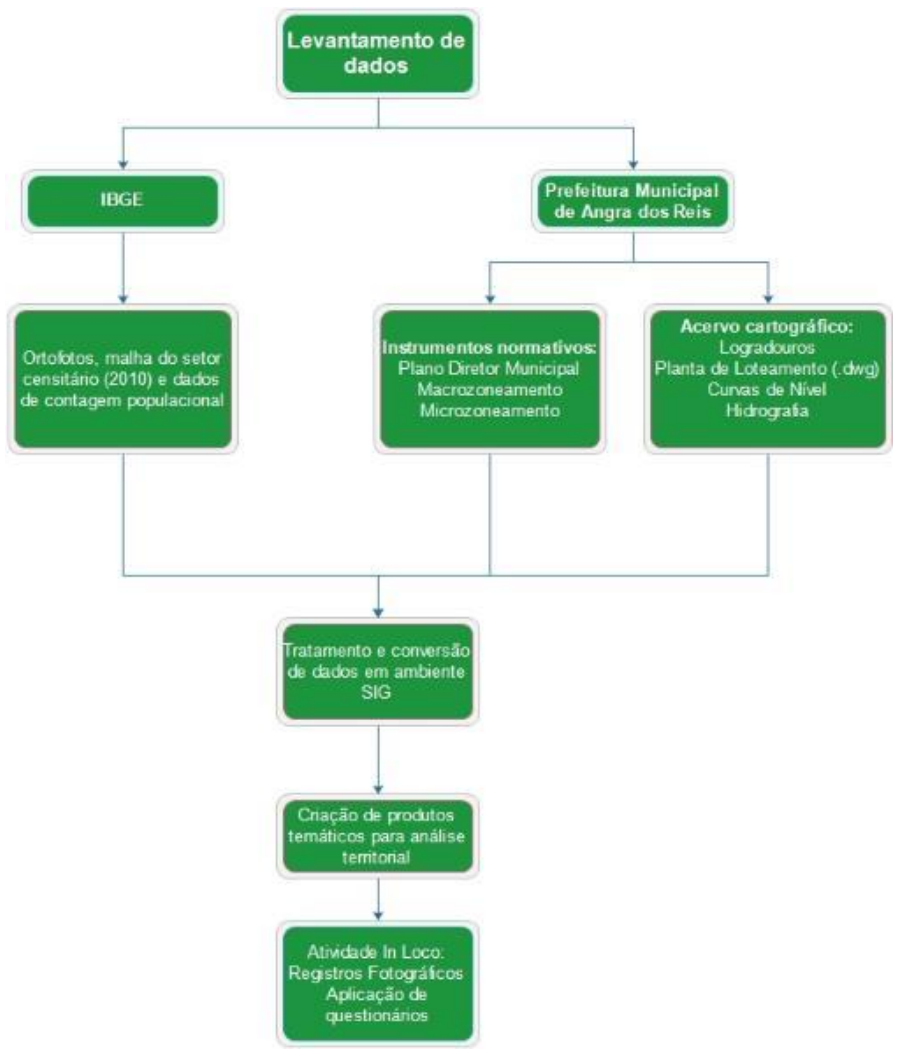

Figura 02 - Fluxograma de trabalho

Em sequência foram realizados trabalhos de campo para avaliação in loco da ocupação, registros fotográficos e aplicação de questionários junto à população residente, 
sendo levantados dados sobre a percepção dos moradores em relação a educação, transporte, saúde, coleta de lixo e atividades culturais e de lazer (Quadro 01).

Quadro 01 - Perguntas adotadas nos questionários aplicados junto aos moradores do loteamento Parque Mambucaba/Angra dos Reis/RJ

\begin{tabular}{|l|l|l|l|}
\hline Quesito & Bom & Regular & Ruim \\
\hline Unidades Hospitalares & & & \\
\hline $\begin{array}{l}\text { Instalações para atendimento de saúde em quantidade } \\
\text { satisfatória? }\end{array}$ & & & \\
\hline Equipamentos médicos em quantidade satisfatória? & & & \\
\hline Instalações atendem as necessidades das demandas? & & & \\
\hline $\begin{array}{l}\text { Equipe da área médica em quantidade satisfatória? } \\
\text { (cardiologia, pediatria,..) }\end{array}$ & & & \\
\hline Leitos hospitalares em quantidade satisfatória? & & & \\
\hline Instalações em qualidade satisfatória & & & \\
\hline Fácil acesso às unidades de saúde & & & \\
\hline & & & \\
\hline Unidades Escolares & & & \\
\hline Unidades escolares em quantidade satisfatória & & & \\
\hline Unidades escolares em qualidade satisfatória & & \\
\hline Corpo docente atende às demandas? & & & \\
\hline Instalações escolares em qualidade satisfatória? & & & \\
\hline Acesso fácil e rápido às unidades escolares? & & & \\
\hline Espaços de convívio em quantidade satisfatória? & & & \\
\hline & & & \\
\hline Coleta de Lixo, Transporte, Cultura e Lazer & & & \\
\hline Coleta de lixo em quantidade satisfatória? & & & \\
\hline Vias de circulação em quantidade satisfatória & & & \\
\hline Meios de transporte em quantidade satisfatória & & & \\
\hline Meios de transporte em qualidade satisfatória & & & \\
\hline Meios de transporte com freqüência satisfatória & & \\
\hline $\begin{array}{l}\text { Espaços de cultura e lazer (Cinema, praças, clube, } \\
\text { biblioteca) em quantidade satisfatória? }\end{array}$ & & & \\
\hline
\end{tabular}

\section{CONSIDERAÇÕES SOBRE O PARQUE MAMBUCABA E A LEGISLAÇÃO URBANÍSTICA MUNICIPAL}

De forma a orientar o crescimento e a ocupação urbana municipal, os dispositivos legais que coordenam as ações sobre o território estabeleceram funções diversas de uso e ocupação do solo, com a prerrogativa de um desenvolvimento urbano que possibilitasse maior qualidade de vida para a população. Um dos mais importantes dispositivos é o plano diretor urbanístico - instrumento de planejamento que tem por função sistematizar o desenvolvimento físico, econômico e social do território municipal, visando o bemestar da comunidade local.

Em Angra dos Reis, o Plano Diretor Urbanístico foi instituído através da Lei Municipal de $\mathrm{n}^{\circ}$ 1754, de 21 de dezembro de 2006. Em seu Capítulo I - Da Conceituação, o art. $1^{\circ}$ descreve: 
Art. $1^{\circ}$. O Plano Diretor abrange todas as áreas emersas $e$ imersas do Município de Angra dos Reis incluindo a projeção da plataforma continental correspondente ao Município, regulamentando seu uso e ocupação de acordo com as disposições contidas nos instrumentos de planejamento e gestão que compõem sua estrutura.

No que tange ao Capítulo III - Diretrizes do Plano Diretor Urbanístico, destaca-se o item III, que menciona a área em estudo:

III - estabelecer a incidência do parcelamento, edificação ou utilização compulsórios sobre os imóveis que configurarem solo urbano não edificado, subutilizado ou não utilizado, localizados nas Macrozonas de Ocupação Urbana dos bairros Parque Perequê, Parque Mambucaba, Frade, Pontal, Praia da Ribeira, Nova Angra, Japuíba, Centro, Praia do Anil, Balneário, Parque das Palmeiras, Praia da Chácara, Camorim, Verolme, B.N.H., Village e Monsuaba(...)

O Plano Diretor Municipal deu diretrizes para a área do Parque Mambucaba, reconhecendo-a como uma macrozona urbana, direcionando o crescimento da área em questão para a moradia e espaços públicos de lazer, visto o crescimento exponencial ao longo dos anos, muito em função da implantação e funcionamento das Usinas Nucleares Angra I e II.

Após a aprovação do Plano Diretor urbanístico Municipal, as Leis complementares a este dispositivo foram criadas para atuar no território em diferentes escalas, de forma a auxiliar no planejamento urbano da cidade. Uma delas é a Lei de Zoneamento, instituída como Lei Municipal n²091 de 23 de janeiro de 2009. Em seu Capítulo I - Das Disposições Preliminares, o Art. $1^{\circ}$ descreve:

Art. $1^{o}$. Esta Lei tem por objetivo a divisão do Território Municipal em parcelas distintas por suas características físicas, sociais e econômicas, de modo a dar-lhes adequado tratamento urbanístico e ambiental, visando assim melhor cumprir as diretrizes expressas no Plano Diretor Municipal, do qual é instrumento normativo.

Assim sendo, o Município de Angra dos Reis foi dividido em quatro (04) macrozonas, cada qual com suas características e funções distintas. O Parque Mambucaba foi inserido na Macrozona Urbana (MZU), definida como "áreas efetivamente utilizadas para fins urbanos, nas quais recursos ambientais, em função da urbanização, foram alterados ou suprimidos, compreendendo as áreas já parceladas e as glebas destinadas ao crescimento urbano, que ainda não foram objetos de parcelamento do solo (item II, art 4 da Lei Municipal n²091/2009)".

A Lei de Zoneamento também repartiu as Macrozonas em subdivisões chamadas de Unidades Territoriais (UT's). São 12 UT's, criadas com o intuito de ordenar oMacrozoneamento, Zoneamento e Microzoneamento Municipal. Cada unidade territorial consiste em uma área delimitada inserida numa Macrozona. No caso do Parque Mambucaba, a unidade territorial na qual ele está inserido é a Unidade Territorial 01 (UT01). 
Os demais artigos deste mesmo capítulo estabelecem a definição de cada Zona citada no artigo $7^{\circ}$.

Para auxiliar na compreensão de divisão territorial e suas funções, o esquema da figura 03 mostra, o macrozoneamento e o zoneamento de Angra dos Reis.

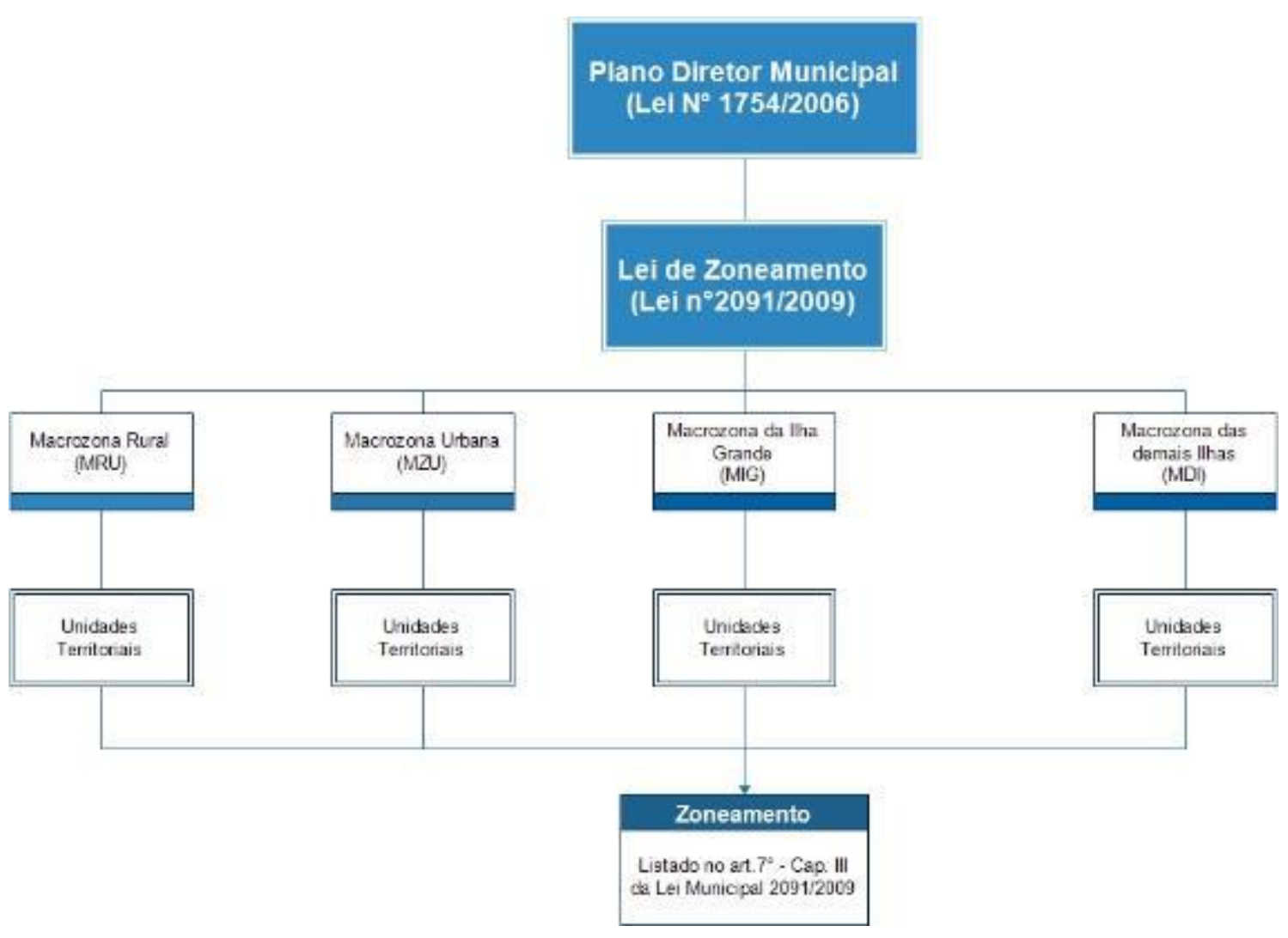

Figura 03: Organização do Macrozoneamento e Zoneamento Municipal

É importante ressaltar que nem todas as UT'S possuem a mesma quantidade e tipo de Zonas. Essa classificação é criada a partir da visão da gestão pública sobre o cenário do Município, analisando diversos fatores de modificação espacial, como vetores de crescimento, riscos ambientais, mobilidade urbana, entre outros. E como o Plano Diretor e suas Leis Complementares têm uma validade de uma década, as Zonas representam as intenções do Poder Público sobre o futuro do Município.

O Parque Mambucaba, inserido na MZU e na UT-01, apresenta as seguintes Zonas: Zonas Residenciais 1, 2 e 3; Zona de Interesse Social; Zonas Comerciais 1,2,3 e 4, Zona de Interesse Turístico 2; Zona de Interesse Ambiental de Proteção; e Zona de Interesse Ambiental e de Ocupação Coletiva (Quadro 2). 
Quadro 02: Zoneamento do Parque Mambucaba/Angra dos Reis/RJ

\begin{tabular}{|c|c|}
\hline \multicolumn{2}{|c|}{$\begin{array}{l}\text { Parque Mambucaba } \\
\text { (MZU - UT01) }\end{array}$} \\
\hline Zona & Definição \\
\hline Zona Residencial 1 (ZR-1) & $\begin{array}{l}\text { Zona de ocupação do uso do solo com } \\
\text { característica residencial unifamiliar. }\end{array}$ \\
\hline Zona Residencial 2 (ZR-2) & $\begin{array}{l}\text { Zona de ocupação de solo com } \\
\text { característica residencial multifamiliar } \\
\text { vertical. }\end{array}$ \\
\hline Zona Residencial 3 (ZR-3) & $\begin{array}{l}\text { Zona de ocupação do solo com } \\
\text { característica residencial multifamiliar } \\
\text { horizontal. }\end{array}$ \\
\hline $\begin{array}{l}\text { Zonas Especiais de Interesse Social } \\
\text { (ZEIS) }\end{array}$ & $\begin{array}{l}\text { Zonas Especiais de Interesse Social } \\
\text { (ZEIS) são áreas que se caracterizam por } \\
\text { assentamentos de baixa renda irregulares } \\
\text { e consolidados ou áreas subaproveitadas. }\end{array}$ \\
\hline Zona Comercial 1 (ZC1) & $\begin{array}{l}\text { Zona de ocupação do solo com } \\
\text { característica comercial, demarcada } \\
\text { preferencialmente em áreas limítrofes aos } \\
\text { corredores e transversais de bairro, } \\
\text { destinada ao comércio varejista de } \\
\text { pequeno porte e prestação de serviços por } \\
\text { profissionais, liberais autônomos e } \\
\text { pessoas jurídicas. }\end{array}$ \\
\hline Zona Comercial 2 (ZC2) & $\begin{array}{l}\text { Zona de ocupação do solo com } \\
\text { característica comercial, demarcada } \\
\text { preferencialmente em áreas limítrofes aos } \\
\text { corredores e transversais principais de } \\
\text { bairro, e ruas secundárias das zonas } \\
\text { centrais, destinadas ao comércio varejista } \\
\text { até médio porte, e prestação de serviços } \\
\text { por profissionais, liberais autônomos e } \\
\text { pessoas jurídicas. }\end{array}$ \\
\hline Zona Comercial 3 (ZC3) & $\begin{array}{l}\text { Zona de ocupação do solo com } \\
\text { características comerciais, demarcada } \\
\text { preferencialmente em áreas limítrofes aos } \\
\text { corredores de bairro e ruas principais das } \\
\text { zonas centrais, destinadas ao comércio } \\
\text { varejista e prestação de serviços por } \\
\text { pessoas jurídicas. }\end{array}$ \\
\hline Zona Comercial 4 (ZC4) & $\begin{array}{l}\text { Zona de ocupação do solo com } \\
\text { característica comercial destinada ao } \\
\text { comércio varejista e atacadista de médio e } \\
\text { grande porte. }\end{array}$ \\
\hline Zona de Interesse Turístico 2 (ZIT2) & $\begin{array}{l}\text { Zona com características relacionadas ao } \\
\text { ambiente urbano historicamente } \\
\text { preservado, ou com estrutura de lazer }\end{array}$ \\
\hline
\end{tabular}




\begin{tabular}{|c|l|}
\hline \hline & $\begin{array}{l}\text { urbano, destinada ao turismo, com } \\
\text { implantação de meios de hospedagem } \\
\text { com até 40UHs e outros equipamentos de } \\
\text { serviços e apoio à atividade turística. }\end{array}$ \\
\hline Zona de Interesse Ambiental de Proteção \\
(ZIAP) & $\begin{array}{l}\text { A Zona de Interesse Ambiental de } \\
\text { Proteção (ZIAP) caracteriza-se por } \\
\text { possuir atributos naturais de excepcional } \\
\text { beleza cênica ou de importância à } \\
\text { manutenção dos processos ecológicos } \\
\text { essenciais a vida em todas as suas formas, } \\
\text { destinando-se, portanto, à proteção do } \\
\text { Patrimônio Ambiental, Cultural, Histórico } \\
\text { e Paisagístico do Município. }\end{array}$ \\
\hline $\begin{array}{l}\text { Zona de Interesse Ambiental e de } \\
\text { Ocupação Coletiva (ZAOC) érea pública } \\
\text { de Proteção Ambiental que não possui } \\
\text { subdivisões nem pode ser motivo de } \\
\text { parcelamento de solo, sendo destinada ao } \\
\text { uso coletivo de recreação, lazer e estrutura } \\
\text { de apoio turístico, administrado pelo } \\
\text { Poder Público ou sob forma de concessão } \\
\text { para a iniciativa privada. }\end{array}$ \\
\hline Ocupação Coletiva (ZAOC)
\end{tabular}

\section{RESULTADOS ALCANÇADOS}

A partir do cruzamento entre os mapas gerados e a análise da documentação pesquisada foi possível elaborar um diagnóstico da taxa de ocupação dos lotes/loteamento, bem como analisar as áreas de expansão urbana no intervalo temporal sob estudo, e de conflitos de ocupação relacionados as áreas de preservação permanente e as áreas sujeitas a alagamentos, delimitadas pela Defesa Civil municipal.

\section{- Situação do Loteamento em 2005}

Com a sobreposição dos lotes e a ortofoto de 2005 , observou-se que $28 \%$ destes encontravam-se totalmente ocupados, $30 \%$ parcialmente ocupados, e $41 \%$ ainda não ocupados, num total de 2573 lotes (figura 04). 


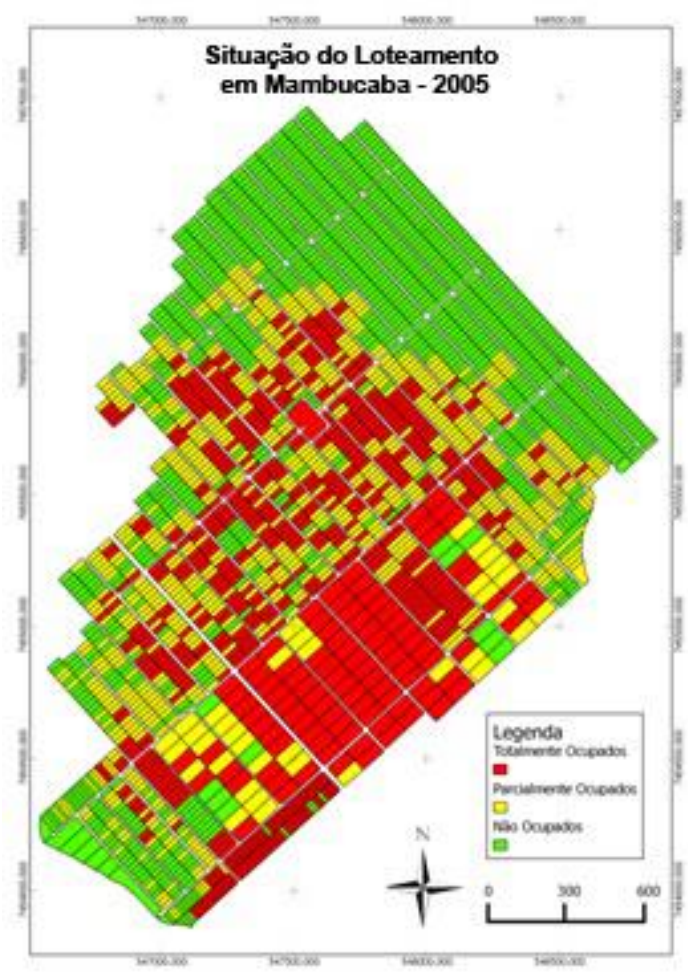

Figura 04. Situação da Ocupação do loteamento Parque Mambucaba em2005 Fonte dos Dados: Prefeitura de Angra dos Reis (Secretaria de Urbanismo)

\section{- Situação do Loteamento em 2016}

Após a sobreposição da planta de loteamento com a imagem de satélite de alta resolução espacial atual (WVII), constatou-se que, dos 2573 lotes aprovados, 47\% estão totalmente ocupados, $20 \%$ parcialmente ocupados e 33\% não ocupados (Figura 05).

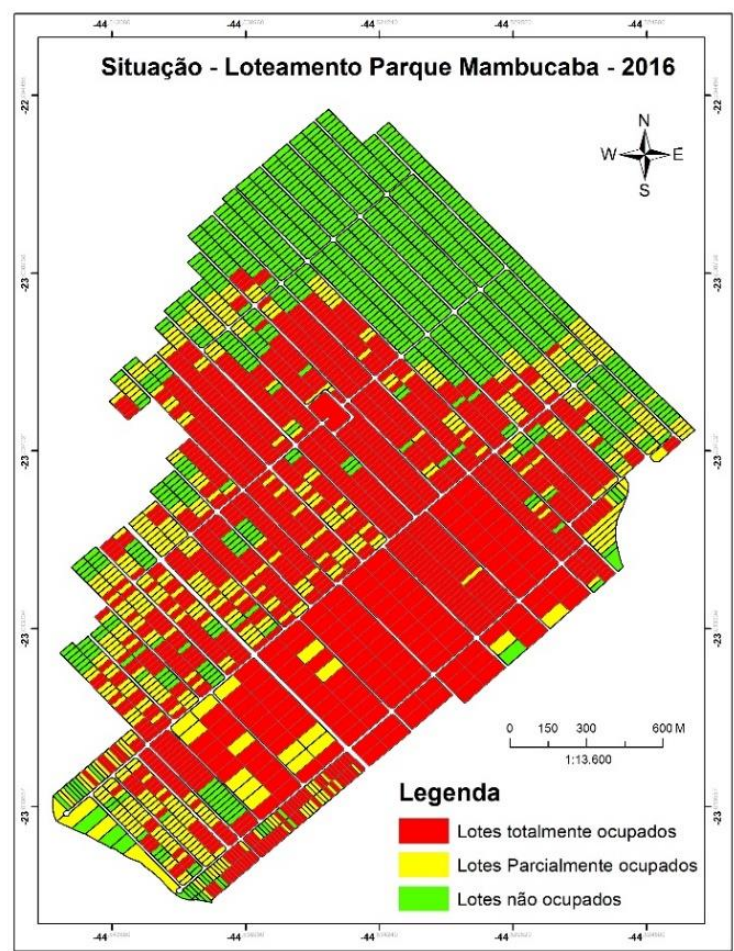

Figura 05. Mapa sobre a situação do loteamento em Mambucaba - 2016 Fonte dos Dados: Prefeitura de Angra dos Reis (Secretaria de Urbanismo) 
Comparando-se as duas datas, observa-se um incremento em termos de ocupação dos lotes de $58 \%$ para $67 \%$, destacando-se o aumento em $19 \%$ dos lotes totalmente ocupados, o que significa também crescimento de áreas impermeáveis em uma região propícia a problemas de transbordamento do rio Mambucaba.

Destaca-se ainda que boa parte dos $33 \%$ de lotes não ocupados encontram-se em área com vegetação nativa e fora do Zoneamento estabelecido pelo Plano Diretor do Município, tratado no item a seguir

\section{- Zoneamento do Parque Mambucaba}

O Parque Mambucaba se enquadra no Zoneamento definido pela Lei Municipal n²091/2009, e suas áreas e respectivos usos encontram-se descritos na tabela 01. Para compreender melhor a distribuição da ocupação na área em questão, sobrepôs-se a situação atual do loteamento com a delimitação do Zoneamento pela Lei supracitada (Figura 06).

A partir desta sobreposição, observou-se que o grande vetor de ocupação foi orientado para as áreas de comércio (ZC'S) e área de interesse turístico (ZIT2), até porque, é onde se localizam os setores de serviços e atividades econômicas. E, no entorno destas áreas, foram delimitadas as Zonas específicas para habitação (ZR'S e ZEIS), que cresceram consideravelmente no período de 2005 a 2016. Mas esse modelo centralizador de bens e serviços, como foi aplicado na Lei de Zoneamento de Angra dos reis, traz algumas consequências no processo de ocupação: $\mathrm{O}$ inchaço urbano nas áreas centrais, e o espraiamento habitacional em seu entorno

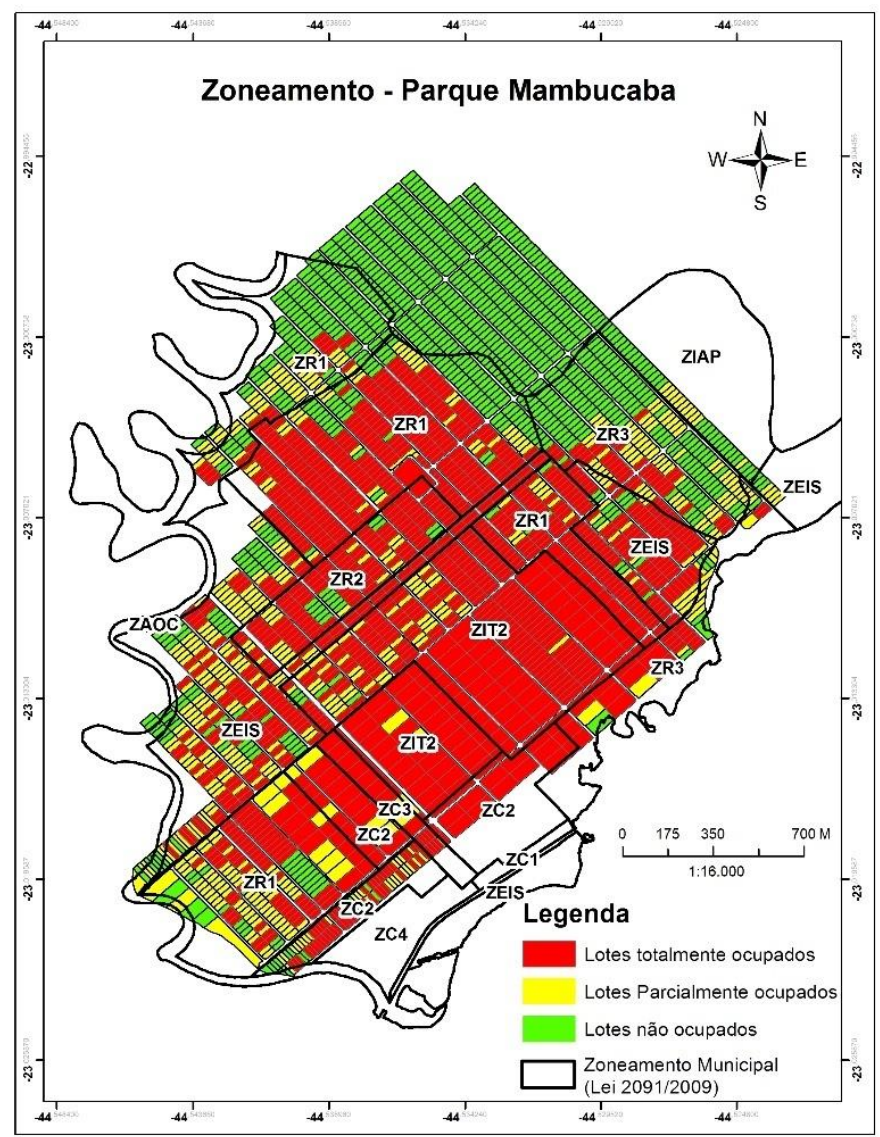

Figura 06. Zoneamento do loteamento Parque Mambucaba sobreposto ao mapa de ocupação urbana em 2016

Fonte dos Dados: Prefeitura de Angra dos Reis (Secretaria de Urbanismo) 
Ressalta-se que sem um planejamento urbano adequado (como programa de mobilidade, saneamento básico, áreas de cultura e lazer), as Zonas Residenciais adquirem uma função única, sem interação com o espaço público e sem movimento de pessoas, trazendo o sentimento de insegurança e até mesmo o aumento de violência nas áreas periféricas.

\section{- Transporte Público no Parque Mambucaba}

Seguindo pela lógica do Zoneamento Municipal, o entorno da área central do loteamento Parque Mambucaba é demarcado por áreas com características habitacionais. Sendo assim, o transporte público se transforma em um importante vetor de mobilidade, que podepromover o deslocamento de pessoas das áreas residenciais ao centro de Bairro. Porém, ao que foi analisado, só existe uma linha de transporte que opera no local, e esta atua apenas nas vias centrais do Bairro (figura 07).

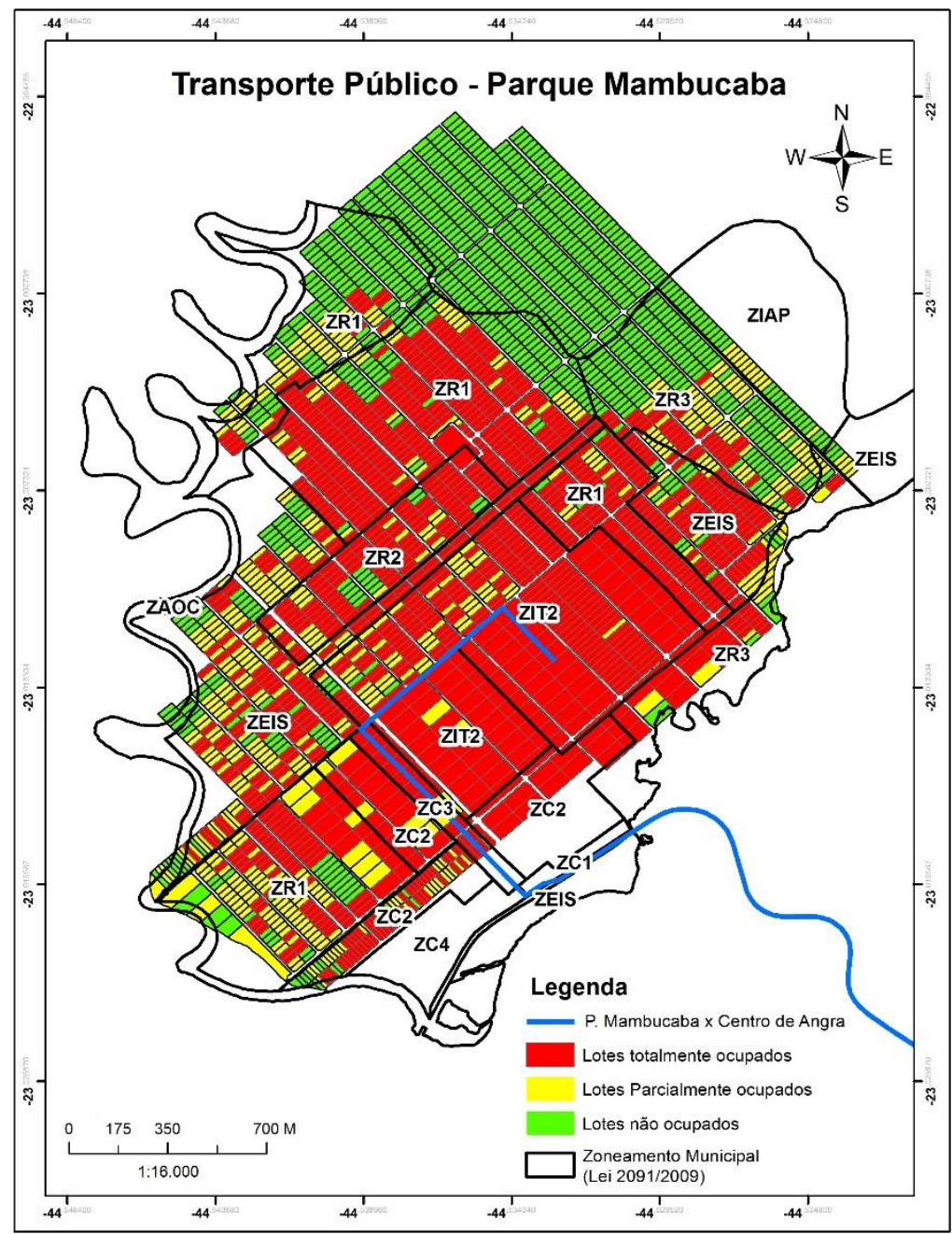

Figura 07. Mapa sobre o transporte no loteamento em Mambucaba - 2016 Fonte dos Dados: Prefeitura de Angra dos Reis (Secretaria de Urbanismo)

\section{- Conflitos de ocupação - Lotes em Área de Preservação Permanente (APP)}

Segundo o Código Florestal (Lei n. ${ }^{\circ} 12.651 / 12$ ), esta categoria de APP, compreende a faixa de $50 \mathrm{~m}$ a partir do leito regular do rio Mambucaba, visto que o mesmo possui mais de 10m de largura. Cruzando-se o mapa de APP - rio Mambucaba com o do loteamento verificou-se que 107 lotes estão em desacordo com a legislação (figura 08). 
Destes, 11 encontram-se totalmente ocupados, 67 parcialmente ocupados e 29 lotes não ocupados, ou seja, 78 lotes em desacordo com a legislação ambiental vigente.

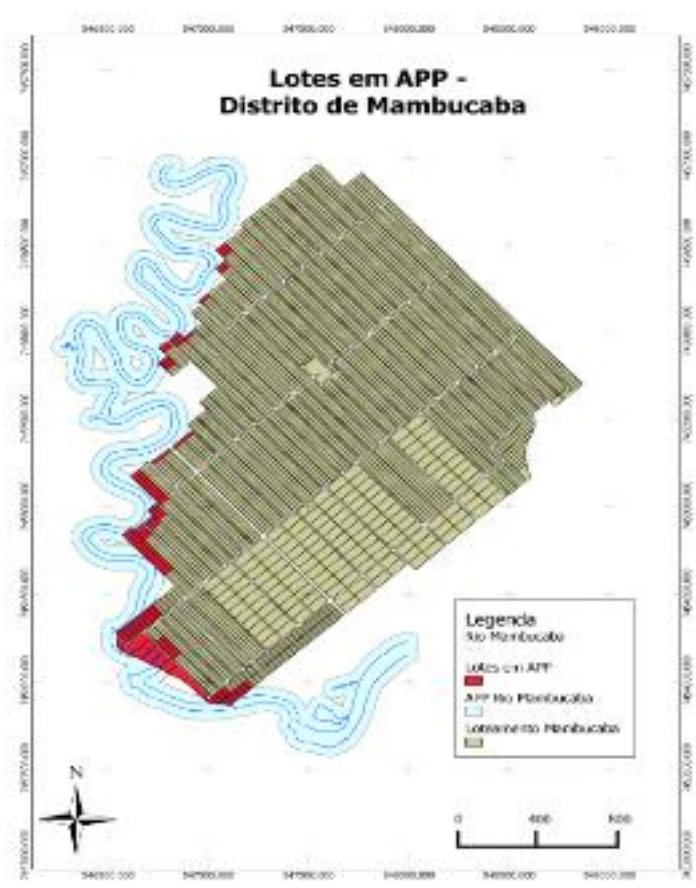

Figura 08. Mapa sobre Lotes em Áreas de Preservação Permanente do rio Mambucaba Fonte dos Dados: Prefeitura de Angra dos Reis (Secretaria de Urbanismo)

\section{- Levantamento de Áreas Sujeitas a Inundações}

Por ser uma localidade sujeita a inundações, foram mapeadas as áreas com maior risco dentro do loteamento, a partir de dados fornecidos pela Defesa Civil Municipal de Angra dos Reis. Observou-se que 47,1\% dos lotes encontram-se em áreas sujeitas a inundações (figura 9). Destes, 391 lotes estão totalmente ocupados, e 468 parcialmente ocupados, indicando a gravidade do problema.

É importante salientar o Zoneamento Municipal neste contexto: grande parte das áreas afetadas por inundações encontra-se em Zonas Residenciais (ZR-2 e ZR-1), ou seja, a ocupação do solo por unidades unifamiliares e multifamiliares é aprovada pelo Órgão Gestor, mesmo a Defesa Civil apontando que essas áreas são sujeitas a ocorrências de inundações. Isso mostra também como é importante as secretarias de governo se comunicarem para que o processo de zoneamento e delimitação de áreas de ocupação seja feito de forma a considerar a configuração natural da própria região, evitando assim perdas humanas e de bens. 


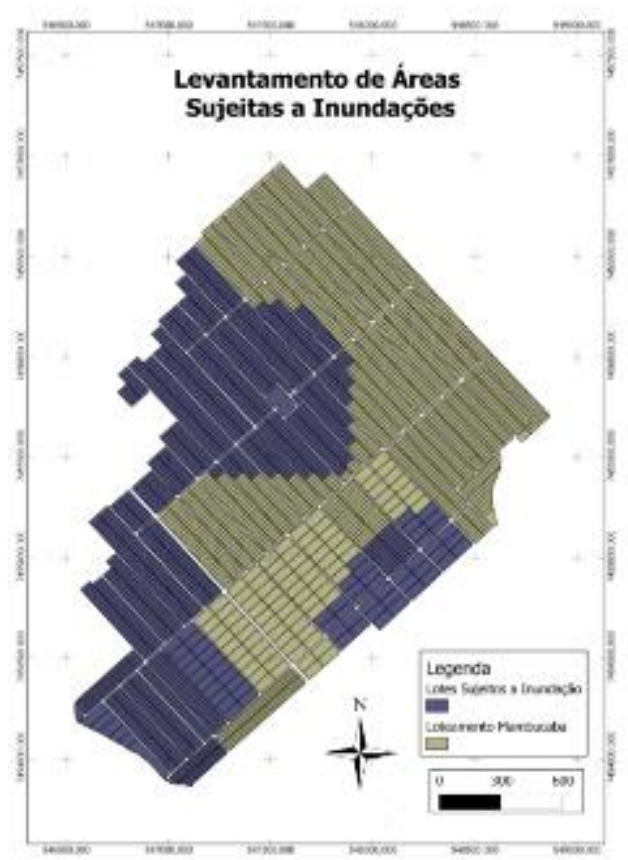

Figura 9. Mapa sobre o Levantamento das Áreas Sujeitas a Inundações

Fonte dos Dados: Prefeitura de Angra dos Reis (Secretaria de Urbanismo e Defesa Civil)

Ao longo dos trabalhos de campo, foram registradas fotos (Figuras 10, 11 e 12) que mostram trechos do loteamento atingidos pelas inundações (Figura 9), bem como partes do rio Mambucaba que sofrem com a erosão de suas margens, afetando em alguns casos construções existentes. Na internet obteve-se imagem da inundação que ocorreu no início de 2010, demonstrando o tamanho do impacto na região (figura 13).

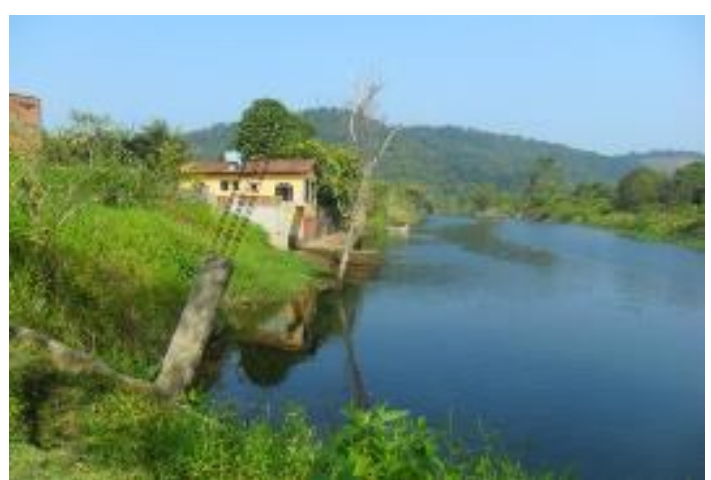

Figura 10- Erosão nas margens do rio Mambucaba

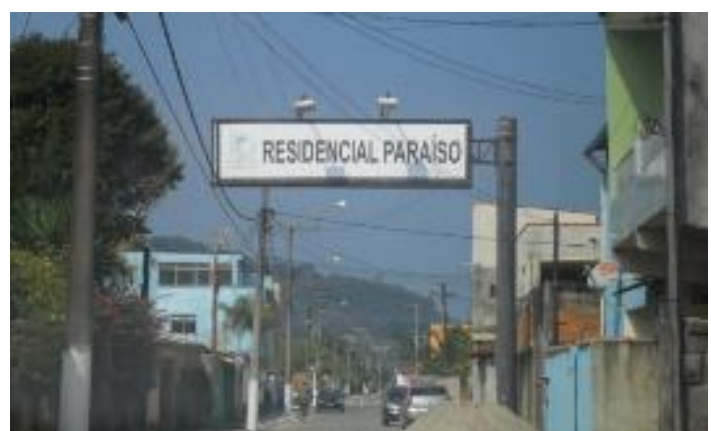

Figura 12- Residencial Paraíso em Mambucaba

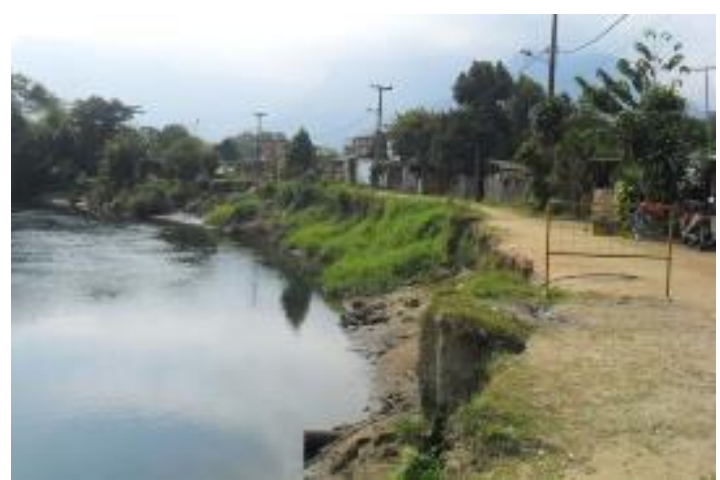

Figura 11- Proximidade de lotes com o rio

- Densidade Demográfica de Mambucaba

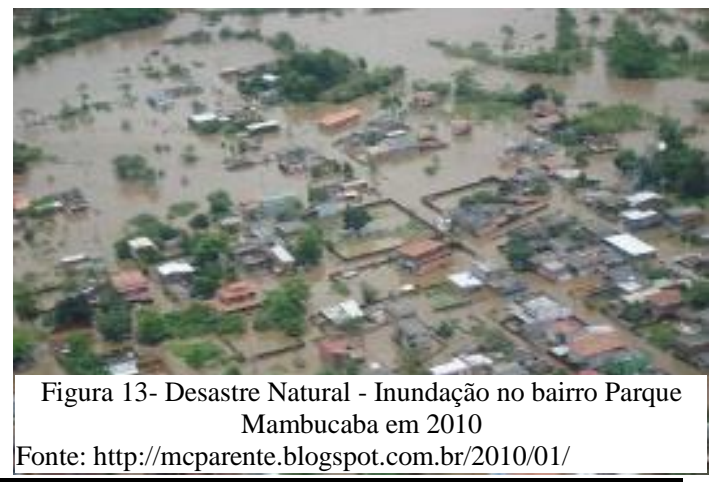

Rev. Tamoios, São Gonçalo (RJ), ano 14, n. 1, págs. 140-157, jan-jun 2018 
A partir dos dados gráficos (malha dos setores) e não gráficos (tabelas) do IBGE de 2010 gerou-se o mapa de densidade populacional em Mambucaba, com as seguintes classes: a) alta densidade ( 77 a 130 hab/ha); média densidade ( 29 a 76 hab/ha) e c) baixa densidade (de 0 a $28 \mathrm{hab} / \mathrm{ha}$ ). Posteriormente sobrepôs-se as áreas sujeitas a inundações (figura 14).

Os resultados apontam a ocorrência de setores censitários com média e alta densidade populacional que se encontram em áreas sujeitas a inundações, indicando os locais que necessitam de maior empenho nos processos de sensibilização junto a população no sentido de uma educação voltada a ocorrência de desastres naturais, bem como apontam também os locais onde deve haver maior atenção nos processos de licenciamento para construção e fiscalização de modo a restringir a ocupação do solo, nesta porção do território.

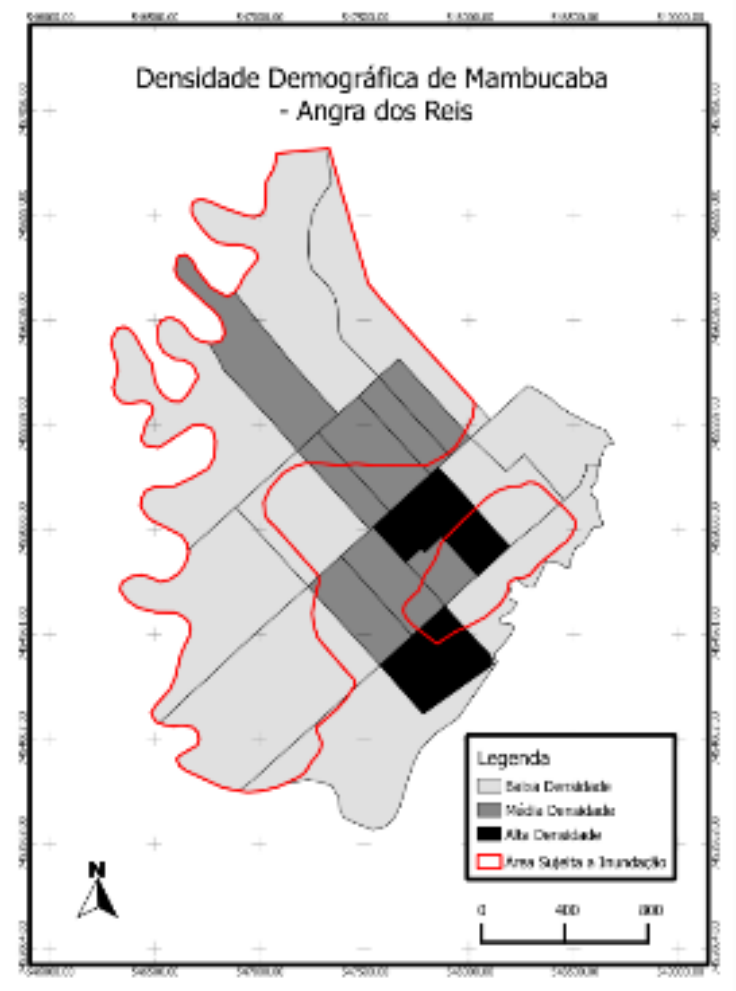

Figura 14. Mapa sobre a Densidade Demográfica de Mambucaba

\section{- Percepção dos Moradores Frente a Infraestrutura Local}

Os questionários focaram a percepção dos moradores sobre os principais serviços e atendimentos públicos tais como as Unidades Hospitalares, Unidades Escolares, Transporte, Cultura e Lazer, e Coleta de Lixo. Buscando-se espacializar ao máximo os locais de análise, os questionários foram aplicados em quatro setores: Norte, Leste, Oeste e Centro, num total de 70 entrevistas.

Os resultados apontam para um descontentamento em relação ao sistema de saúde em Mambucaba (figura 15), considerado falho e mal distribuído, havendo a necessidade, em muitos casos, de deslocamento para o centro de Angra dos Reis ou ao posto de saúde localizado na Praia Brava, bairro contíguo as Usinas e onde residem parte dos técnicos da empresa Eletronuclear.

Já em relação as Unidades Escolares (figura 15) observou-se falta de consenso entre os moradores, apesar de esta área possuir o mesmo problema da saúde, uma vez que 
muitos precisam ir para escolas de outros bairros por falta de vagas. No entanto, ressaltase a inauguração de um CEFET em 2010, oferecendo curso técnico em Pesca, Eletromecânica, e Gestão Ambiental, bem como em nível superior de Engenharia Mecânica.
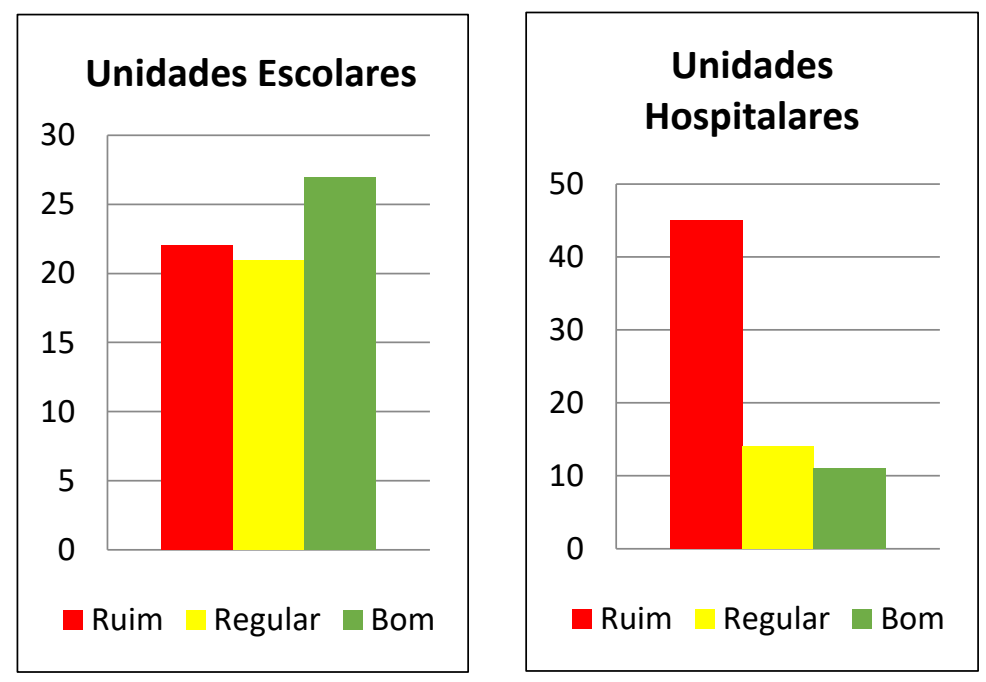

Figura 15. Percepção dos Moradores do Bairro Parque Mambucaba sobre as Unidades Hospitalares e Escolares

Quanto ao transporte (figura 16) houve reclamações principalmente em relação a irregularidade de horários, pelo fato de só haver uma companhia que passa pelo bairro Mambucaba, e o precário estado de conservação da frota.

Também se observou insatisfação em relação à equipamentos e atividades de cultura e lazer (figura 16), ressaltando-se a existência de apenas uma área de recreação em todo o loteamento.
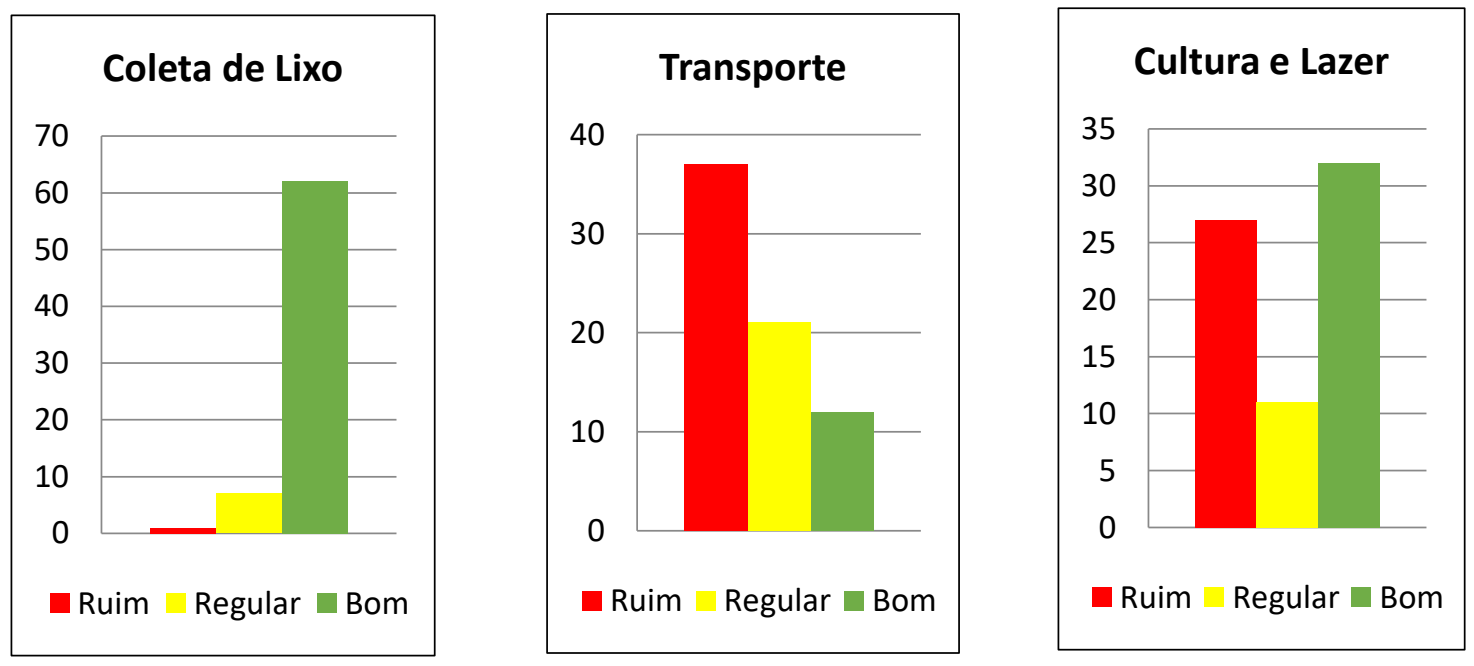

Figura 17. Percepção dos moradores referente aos serviços de Transporte, Cultura e Lazer e de Coleta de Lixo no bairro Parque Mambucaba

Do resultado, destacou-se positivamente apenas a coleta de lixo, sendo considerada satisfatória pela maioria dos moradores. Segundo informado, a coleta de lixo ocorre três vezes na semana. Este fato tem relevância principalmente para os períodos de 
chuva, já que o lixo na rua seria um agravante nos casos de inundações, dificultando o escoamento e aumentando a disseminação de doenças.

\section{CONSIDERAÇÕES FINAIS}

Embora boa parte da baixada urbana do loteamento Parque Mambucaba tenha sido contemplada com um planejamento prévio de ocupação decorrente da aprovação na década de 70, o que difere bastante de outras planícies no município, observam-se conflitos de uso como a ocupação de áreas de preservação permanente, segundo o Código Florestal de 2012. Identificou-se também os locais que, em função da proximidade com o rio Mambucaba, apresentam sérios problemas de enchentes que causam consequências graves à população local como doenças e perda do patrimônio, constandando-se que cerca de $47,1 \%$ do loteamento encontra-se em área de risco. O crescimento populacional também influenciado pela implantação das Usinas Nucleares no distrito, pode ser agravado com a construção da nova unidade (Angra III), afetando ainda mais as demandas por saúde, trabalho, transporte, educação e atividades de cultura e lazer.

No que tange a Legislação Urbanística, o crescimento orientado pela política de Zoneamento deve ser feito de maneira que sejam aprovados usos mistos do solo, promovendo a descentralização de áreas, e com isso, um menor deslocamento populacional para outros bairros e o centro do município. Acrescenta-se aí, a problemática da impermeabilização do solo em local já tão suscetível a ocorrência de enchentes, sendo observado um incremento entre os anos de 2005 e 2016 de 19\% de lotes totalmente ocupados, e, portanto, recomendável uma política de Zoneamento a partir das particularidades da área em questão. O Plano Diretor Urbanístico de Angra dos Reis está para ser modificado, e com isso, a participação popular é de extrema importância no sentido de direcionar a gestão pública no desenvolvimento local.

Ressalta-se ainda a indicação das áreas onde devem ser priorizadas as ações de fiscalização, bem como alertando e sensibilizando a população dos problemas ambientais decorrentes da ocupação de áreas inadequadas tais como as margens do rio Mambucaba, e as áreas sujeitas a alagamentos indicadas pela Defesa Civil Municipal.

\section{BIBLIOGRAFIA CONSULTADA}

ABREU, Cássio Veloso. (2005) Urbanização, apropriação do espaço, conflitos e turismo - um estudo de caso de Angra dos Reis. Dissertação (Mestrado em Arquitetura e Urbanismo) - Programa de Pós-Graduação em Arquitetura e Urbanismo da Universidade Federal Fluminense, Niterói, RJ.

DEFESA CIVIL DE ANGRA DOS REIS. (2011) Levantamento de áreas sujeitas a inundações. Consulta realizada na página http://www.angra.rj.gov.br/asp/index.asp

DENT, B. D.; TORGUSON, J.; HODLER, T. Cartography: Thematic Map Design. 6 ed. McGraw-Hill, Georgia, 2009. 368p.

FRANCISCO, Cristiane Nunes; CARVALHO, Cacilda Nascimento. Disponibilidade hídrica - da visão global às pequenas bacias hidrográficas: $\mathrm{O}$ caso de Angra dos Reis, no Estado do Rio de Janeiro. Revista Geociências, Niterói: Instituto de Geociências. ano 3, $\mathrm{n}^{\circ} 3,13$ p. 2004. 
PREFEITURA MUNICIPAL DE ANGRA DOS REIS, LEI MUNICIPAL N ${ }^{\circ}$ 2091, DE 23 de Janeiro de 2009. Dispõe sobre o Zoneamento Municipal de Angra dos Reis, RJ, Disponível em: <http://www.angra.rj.gov.br/downloads/SMA/LEI\%202091-2009zoneamento\%20do\%20municipio.pdf >. Acesso em: 12 out. 2017.

SAlGADO, Carla Maciel; PEIXOTO, Maria Naíse de Oliveira; MOURA, Josilda Rodrigues Silva. Caracterização espaço-temporal da chuva como subsídio à análise de episódios de enchentes no município de Angra dos Reis, RJ. Revista Geosul, Florianópolis, v. 22, n. 44, p 7-26. jul./dez. 2007. 